\title{
A Study on Exercise Test for Mass Examination of Heart Disease
}

\author{
Mitsuo Kitada, M.D*, Kin-ichi Uheda, M.D*** \\ Tadashi Nakagawa, M.D.,* and Yukimasa Yamaguchi, M.D**
}

\begin{abstract}
One thousand and twenty-two of senior high school students and 274 of primary and junior high school students screened as positive through heart disease mass examination were tested by the Master's two step Method. The results are as follow: 1) In order to get informations to give the guide line for school life, it is still insufficient triple amounts of exercise performed during 3 minutes and 45 seconds for high school male students although this may be appropriate for primary, junior high school students and female senior high school students. 2) Fatigue and their history concerning to athletic activity should not be neglected to evaluate the results of exercise test. 3) It is important to consider before evaluation of the test that QTc immediately after exercise shorten by 6 to $8 \%$ and QTc 3 minutes after the exercise prolonged by 3 to $4 \%$.
\end{abstract}

$\mathbf{R}$ ECOVERY rates of ST-T changes and arrhythmias by mass examination have markedly increased, since ECG examination was included in the primary screening for heart diseases among primary school and high school students, compared to the era when heart disease screening had been carried out with questionnaires, auscultatory findings and X-P findings.

One of the most important things is how to place under suitable supervision in daily school life these cases found by the above mentioned screening. In order to decide the guide line for supervision in school life, especially for students with ECG abnormalities, exercise test is inevitable.

Exercise test according to sophisticated approaches such as maximal or submaximal exercise is limited for mass examinations basis. Therefore, rather simple methods are practical for mass examination purpose.

Judging from amounts of activity of primary school or high school students in daily life, the

Key Words:

Heart disease mass examination for students

Master's two step test

Heart rate

QTc present authors considered that double two step test is not sufficient, therefore, had adopted triple amounts of Master's two step test performed during 3 minutes and 45 seconds in order to bring their heart rates to the reasonable points.

In this paper the authors described the results of exercise test done according to our way described above.

\section{SUBJECTS AND METHODS}

The subjects are 1,022 of senior high school students and 274 of primary or junior high school students who were screened as positive by our mass examination.

Subjects were exercised during 3 minutes and 45 seconds on two step staircase with triple amounts of standard Master's test requirement after giving instruction so that the test to be completed as programed.

ECG were recorded at rest, immediately and 3 minutes after exercise test. Time lag between start of recording ECG and termination of the exercise was 11.5 seconds on an average.

Before and after the test informations concerning to the examinees' physical condition,

*The Center for Adult diseases, Osaka, **Division of Cardiology, Children's Medical Center of Osaka Japan

Mailing address: Mitsuo Kitada, M.D., The Center for Adult Diseases, 1-3-3 Nakamichi, Higashinari-ku, Osaka 537 Japan 
TABLE I HEART RATE BY SEX AND AGE GROUP

\begin{tabular}{|c|c|c|c|c|c|c|c|c|}
\hline \multirow{2}{*}{ Sex } & \multirow{2}{*}{ School } & \multirow{2}{*}{ No. of cases } & \multicolumn{2}{|c|}{ at rest } & \multicolumn{2}{|c|}{ immed. after exercise } & \multicolumn{2}{|c|}{3 min. after exercise } \\
\hline & & & mean & $S D$ & mean & $S D$ & mean & $S D$ \\
\hline \multirow[t]{3}{*}{ male } & primary school & 66 & 80.4 & 15.2 & 133.3 & 28.1 & 92.3 & 19.0 \\
\hline & junior highs. & 51 & 77.8 & 13.6 & 131.4 & 23.2 & 91.4 & 17.4 \\
\hline & senior high s. & 505 & 66.1 & 13.9 & 107.9 & 23.7 & 77.0 & 16.0 \\
\hline \multirow[t]{3}{*}{ female } & primary school & 66 & 82.4 & 17.2 & 140.2 & 22.4 & 98.8 & 19.1 \\
\hline & junior highs. & 91 & 81.8 & 14.4 & 141.7 & 19.0 & 98.9 & 15.4 \\
\hline & senior highs. & 517 & 72.6 & 15.1 & 132.9 & 21.9 & 87.2 & 18.8 \\
\hline
\end{tabular}

TABLE II RATIO OF HEART RATES AFTER EXERCISE AND AT REST BY SEX AND AGE GROUP

\begin{tabular}{|c|c|c|c|c|c|c|}
\hline \multirow{2}{*}{ Sex } & \multirow{2}{*}{ School } & \multirow{2}{*}{ No. of cases } & \multicolumn{2}{|c|}{$\begin{array}{c}H R \text { immed. after exercise } \\
\text { /HR at rest }\end{array}$} & \multicolumn{2}{|c|}{$\begin{array}{c}H R 3 \text { min after exercise } \\
/ H R \text { at rest }\end{array}$} \\
\hline & & & mean & $S D$ & mean & $S D$ \\
\hline \multirow[t]{3}{*}{ male } & primary school & 66 & 1.79 & 0.38 & 1.19 & 0.26 \\
\hline & junior highs. & 51 & 1.80 & 0.33 & 1.23 & 0.20 \\
\hline & senior highs. & 505 & 1.75 & 0.33 & 1.24 & 0.22 \\
\hline \multirow[t]{3}{*}{ female } & primary school & 66 & 1.80 & 0.36 & 1.23 & 0.23 \\
\hline & junior highs. & 91 & 1.85 & 0.28 & 1.29 & 0.21 \\
\hline & senior highs. & 517 & 1.92 & 0.33 & $1.2 \dot{8}$ & 0.22 \\
\hline
\end{tabular}

weariness, their daily school life etc. were gathered by questionaire and by direct interview.

\section{RESULTS}

Table I shows heart rate at rest and after exercise by sex and school grade. In both sexes senior high school students showed significantly lower heart rate compared to primary and junior school students. Especially male senior high school students showed significantly lower increment of heart rate after exercise compared to male primary and junior high school students.

Table II shows ratio of heart rate after exercise to those at rest. In the male senior high school students, ratio immediately after exercise was smaller compared to primary and junior high school students. In the female senior high school students the ratio was higher, although statistically insignificant. The ratio 3 minutes after exercise showed almost aimilar trends.
Table III shows QTc before, immediately and 3 minutes after the test by sex and school grade. In both sexes QTc at correspond time showed no significant difference between different graders. QTc immediately after the test was significantly shorter than that at rest in every group. QTc 3 min after exercise was significantly longer.

Table IV shows relationship between heart rate and history of athletic activity among high school students. The longer the period of athletic activity, the lower the heart rate at rest and lesser increment of heart rate immediately after the test and faster tendency to return to heart rate at rest after 3 minutes. The above mentioned trends were more prominent in males than in females.

Table $\mathrm{V}$ showed the relationship between heart rate and subjective weariness stated by examinees before starting the test. The subjects with more weariness showed lower heart rate at rest and tendency toward lesser increment of 
TABLE III QTC BY SEX AND AGE GROUP

\begin{tabular}{|c|c|c|c|c|c|c|c|c|}
\hline \multirow{2}{*}{ Sex } & \multirow{2}{*}{ School } & \multirow{2}{*}{ No. of cases } & \multicolumn{2}{|c|}{ at rest } & \multicolumn{2}{|c|}{ immed. after exercise } & \multicolumn{2}{|c|}{3 min. after exercise } \\
\hline & & & mean & $S D$ & mean & $S D$ & mean & $S D$ \\
\hline \multirow[t]{3}{*}{ male } & primary school & 66 & 39.8 & 2.8 & 36.9 & 2.5 & 40.9 & 3.1 \\
\hline & junior highs. & 51 & 39.9 & 2.2 & 36.8 & 2.0 & 41.2 & 2.9 \\
\hline & senior highs. & 505 & 39.2 & 2.9 & 37.3 & 2.2 & 40.9 & 3.3 \\
\hline \multirow[t]{3}{*}{ female } & primary school & 66 & 39.9 & 2.0 & 36.9 & 2.2 & 40.7 & 3.2 \\
\hline & junior highs. & 91 & 40.2 & 2.9 & 36.8 & 1.2 & 41.5 & 1.9 \\
\hline & senior high s. & 517 & 39.6 & 2.8 & 37.4 & 1.7 & 41.4 & 2.8 \\
\hline
\end{tabular}

TABLE IV HISTORY OF ATHLETIC ACTIVITY AND HEART RATE (senior high school student)

\begin{tabular}{|c|c|c|c|c|c|c|c|c|}
\hline \multirow{2}{*}{ Sex } & \multirow{2}{*}{ Athletic activity } & \multirow{2}{*}{ No. of cases } & \multicolumn{2}{|c|}{ at rest } & \multicolumn{2}{|c|}{ immed. after exercise } & \multicolumn{2}{|c|}{3 min. after exercise } \\
\hline & & & mean & $S D$ & mean & $S D$ & mean & $S D$ \\
\hline \multirow[t]{4}{*}{ male } & sport club $>=2$ yrs. & 284 & 64.0 & 13.6 & 103.9 & 22.7 & 73.5 & 15.5 \\
\hline & sport club $<2 y r s$ & 75 & 66.3 & 12.5 & 110.5 & 21.7 & 80.2 & 17.0 \\
\hline & no membership & 125 & 69.9 & 13.9 & 113.1 & 23.5 & 81.4 & 15.5 \\
\hline & daily life restricted & 7 & 75.6 & 10.2 & 139.0 & 16.8 & 93.4 & 10.3 \\
\hline \multirow[t]{4}{*}{ female } & sport club $>=2 y r s$ & 205 & 69.8 & 14.1 & 128.1 & 22.0 & 84.3 & 18.4 \\
\hline & sport club $<2$ yrs. & 92 & 70.7 & 14.2 & 128.5 & 22.9 & 83.7 & 18.6 \\
\hline & no membership & 181 & 76.5 & 15.5 & 139.7 & 20.6 & 92.3 & 18.6 \\
\hline & daily life restricted & 14 & 73.7 & 15.0 & 144.8 & 12.9 & 93.1 & 19.2 \\
\hline
\end{tabular}

TABLE V SUBJECTIVE WEARINESS AND HEART RATE (senior high school student)

\begin{tabular}{|c|c|c|c|c|c|c|c|c|}
\hline \multirow{2}{*}{ Sex } & \multirow{2}{*}{ Weariness } & \multirow{2}{*}{ No. of cases } & \multicolumn{2}{|c|}{ at rest } & \multicolumn{2}{|c|}{ immed. after exercise } & \multicolumn{2}{|c|}{3 min. after exercise } \\
\hline & & & mean & $S D$ & mean & $S D$ & mean & $S D$ \\
\hline \multirow[t]{3}{*}{ male } & none & 286 & 66.9 & 14.1 & 110.1 & 23.3 & 78.5 & 16.3 \\
\hline & slight & 206 & 65.1 & 13.7 & 105.7 & 23.6 & 75.3 & 15.9 \\
\hline & $>$ moderate & 13 & 62.2 & 8.7 & 96.6 & 14.7 & 70.8 & 15.1 \\
\hline \multirow[t]{3}{*}{ female } & none & 318 & 73.6 & 14.9 & 135.1 & 21.1 & 88.7 & 17.8 \\
\hline & slight & 186 & 71.0 & 14.7 & 129.6 & 22.7 & 85.3 & 19.5 \\
\hline & $>$ moderate & 12 & 67.5 & 11.7 & 127.3 & 21.7 & 79.0 & 18.4 \\
\hline
\end{tabular}

heart rate immediately and 3 minutes after the test, although the difference was not statistically significant.

Table VI summarized the results of the exercise test by category of background diseases.
The cases with improvement or deterioration of ECG findings after the test were encountered more in female than in males, although the difference was not statistically significant. 
TABLE VI RESULTS OF EXERCISE TEST BY SEX AND BY CATEGORY (senior high school students)

\begin{tabular}{lcccccccc}
\hline \hline \multirow{2}{*}{ Category } & \multicolumn{2}{c}{ No. of cases } & \multicolumn{2}{c}{ no changes } & \multicolumn{3}{c}{ improved } & \multicolumn{2}{c}{ deteriorated } \\
& $M$ & $F$ & $M$ & $F$ & $M$ & $F$ & $M$ & $F$ \\
\hline organic H.D. & 52 & 50 & 48 & 42 & 2 & 4 & 2 & 4 \\
border line & 45 & 69 & 41 & 42 & 2 & 21 & 2 & 6 \\
arrhythmia & 262 & 228 & 90 & 62 & 157 & 147 & 15 & 19 \\
history of arrhy. & 15 & 31 & 7 & 18 & - & - & 8 & 13 \\
others & 7 & 26 & 7 & 26 & - & - & - & - \\
normal & 124 & 113 & 123 & 109 & 1 & 4 & - & - \\
\hline total & 505 & 517 & 316 & 299 & 162 & 176 & 27 & 42 \\
(\%) & $(100)$ & $(100)$ & $(63)$ & $(58)$ & $(32)$ & $(34)$ & $(5)$ & $(8)$ \\
\hline
\end{tabular}

$H D=$ heart disease $;$ arrhy $=$ arrhythmia $M=$ male $; F=$ famale

\section{DISCUSSION}

In order to evaluate cardiac state of the students with arrhythmia or ST-T changes or postoperative cases so that appropriate guide line for school life were drawn, it is important to test those students with their heart rate bringing up to the reasonable points. In the preliminary study, we confirmed that triple amounts of Master's two step test performed during 3 minutes and 45 seconds is necessary for attaining heart rates sufficient to evaluate their cardiac status among primary school or junior high school students.

As shown in the Table I, male and female senior high school students showed lower heart rates than younger age group did after exercise with this amounts of load. Judging from this results amounts of exercise seemed to be deficient for senior high school students. Maximal heart rates are said to be almost similar for primary, junior and senior high school students. However, heart rates at rest are different as shown in the Table I between different age groups.

As shown in Table II in the male, senior high school students showed smaller ratio of heart rate after exercise to that at rest than younger age groups. In the female the same ratio is reversed.

The results shown in Table VI again favour the concept that the amounts of exercise given for senior high school male students was insufficient, namely in male senior hign school students the number of cases with any changes (improvement or deterioration) was smaller compared to that observed in female senior high school students (this conclusion may sound too much simplified, because severity of diseases are not always similar between both sexes).

Although being not tabulated, according to the questionaires concerning to the hardness of the exercise, $74 \%$ of female senior high school students answered that the exercise was almost similar to harder part of preparation exercise before starting exercise in school, on the other hand $81 \%$ of male senior high school students stated it was similar to the mild preparation exercise.

Concerning to the amounts of exercise reasonable for male senior high school students it still remained undetermined, however, triple amounts of Master's two step requirement performed during 3 minutes and 15 seconds was tentatively adopted to be reasonable.

Heart rates immediately after the exercise by the above mentioned method was $128+22.3$ / min on an average for 50 male senior high school students.

In order to determine the amounts of exercise by Master's method age, sex and body weight are the factors concerned. We consider body weight should be replaced by certain obesity index so that factor related to body statue can be included.

As generally accepted, well trained active athletes showed less increment of heart rate after exercise and quick tendency to return to heart rate at rest? Our subjects of the present study showed same results.

Japanese Circulation Journal Vol. 49, December 1985 
As shown in Table $\mathrm{V}$, heart rate after exercise of the subjects with feeling of weariness did not show similar trend to increase as the subjects without feeling of weariness.

Our explannation is that in individual with feeling of weariness heart rates may be depressed to lower rates via autonomic nerve control.

The results of reexamination of those with feeling of weariness at the first time showed same trend with those without feeling of weariness at the first examination, if they had no feeling of weariness at the time of reexamination. Relationship between heart rate and sleeping hour was found not statistically related in this study.
As shown in Table III, QTc shortened by $6-8 \%$ immediately after exercise when compared to that of calculated at rest and elongated by $3-4 \%$ 3 minutes after exercise. This is an important points when one evaluates QTc.

\section{REFERENCES}

1. MIYAMURA M, HONDA Y: Maximum cardiac output related to sex and age. Jap J Physiol 23: 645,1973

2. KARVONEN MJ, KENTALA E, MUSTALA O: The effects of training on heart rate: A longitudinal study. Ann Med Exper Biol Jenn 35: 307, 1957 